\title{
THREE QUARTERS OF A LOOP: CO-OP WORK TERM EVALUATIONS AND WORK REPORTS TO MEASURE THE COMMUNICATION ATTRIBUTE
}

\author{
A. Milne, M. Pirnia, D. Wright, R. Al-Hammoud, J. Grove \\ University of Waterloo \\ mpirnia@uwaterloo.ca, ajbmilne@uwaterloo.ca,derek.wright@uwaterloo.ca, ralhammoud@uwaterloo.ca, \\ jason.grove@uwaterloo.ca
}

\begin{abstract}
This research analyzes the available data (student work term evaluations performed by employers, and work reports evaluated by the program) to triangulate and understand student performance on the $\mathrm{CEAB}$ Communication attribute. In this way we aim to innovate in the field of co-operative education to leverage the diverse work experiences of our students and understand their diverse backgrounds to suggest means of improving their communication skills. In this paper, we analyze employer feedback by grouping responses in several ways (binning by engineering program, term of study, level of performance, and criteria) to assess student performances at the faculty and program levels. We also assess student work reports for communication and analytical skills. We find a notable contrast between the evaluations given for the performance criteria. Students appear to perform at a higher level in areas such as Interpersonal Communication, Teamwork, and Appreciation of Diversity, while evaluations for criteria such as Problem Solving and Oral and Written Communication are relatively lower. This is supported by work report assessments showing that some students continue to struggle with written communication and analysis. Future work will include focus groups with employers and students to add meaning to the data. Throughout the process, writing and communication experts are involved to help interpret data and recommend solutions.
\end{abstract}

Keywords: CEAB Graduate Attributes, Continual Improvement, Closing the Loop, Communication, Co-op Employer Evaluation, Work Term Report, Triangulation

\section{INTRODUCTION}

All University of Waterloo Engineering undergraduate students participate in an extensive co-op program that allows them to apply their academic knowledge within diverse industries. Employers evaluate students' performance after each work term, using an evaluation $\underline{\text { form }}$ that outlines 16 technical and professional criteria including communication, with performance indicators ranging from Developing (1-2), to Good (3-5), to Superior (6-7). Concurrently, after three of these six work terms, students write an analytical 'work report' outlining their experiences, solutions provided, and lessons learnt.

This research analyzes the available data to triangulate and understand student performance on communication, which is one of the attributes that the Canadian Engineering Accreditation Board (CEAB) requires engineering students to possess upon graduation. In this way, we aim to innovate in the field of co-operative education to leverage the diverse work experiences of our students and understand their backgrounds to suggest means of improving their communication skills. This research also serves as a trial of the use of these data sources to set a framework for assessing other CEAB attributes. To this end, we also suggest modifications to the feedback form and work report requirements.

\section{METHOD}

As the focus of this paper is student communication skills, we focused on this aspects in our available data sources. Further, we focus on written (rather than oral, inter-personal, graphical, etc) communication. The data sources used to perform the analysis were student performance evaluation forms filled out by co-op employers, and co-op work-term reports (assessed by professors and/or teaching assistants after student return to campus. We compare these two different evaluation methods to add meaning through triangulation, and as a preparation for employer and student focus groups to add meaning to the data.

\subsection{Co-op Student Performance Evaluation}

At the end of each work semester, employers must evaluate, "The extent to which the student demonstrates effective written communications", for each engineering 
student as part of their co-op evaluation. The performance indicators range from 1 to 7 , and "not observed", with one the lowest evaluation and seven the highest one. The provided rubrics for each numerical evaluation are:

- Developing performance (1 and 2): Not consistently clear and concise or requires frequent checking and editing

- $\quad$ Good performance (3, 4 and 5): Normally clear, well organized and understandable and needs only moderate checking and editing

- $\quad$ Superior performance (6 and 7): Always clear, well organized and easily understandable; rarely requires checking and editing

In analyzing work term employer evaluations we analyzed employers' feedback by grouping responses (e.g. binning by engineering program, term of study, level of performance, and overall evaluation) to assess student performances at the faculty and program levels.

\subsection{Work-Term Reports}

As part of the co-op process, students are required to submit a work-term report after three of their 6 work terms (with submissions spread across the curriculum). These reports are evaluated by the students' department. Since each department has its own rubric and methods of co-op report evaluations, we focus in this paper on two of the engineering departments. For confidentiality, we will call them program 1 and program 2 in this paper. All departments grade their students' reports on a combination of at least communication and analysis skills. As such, the techniques described in this paper should be applicable to other departments.

\section{FINDINGS}

The findings highlight a notable contrast between the evaluations of different attributes. Employers rate students at a higher level in areas such as Interpersonal Communication, Teamwork, and Appreciation of Diversity, while evaluations for criteria such as Problem Solving and Oral and Written Communication are relatively lower. This is supported by work report assessments showing that some students continue to struggle with written communication and analysis.

\subsection{Co-op Performance Evaluation}

The co-op performance evaluations demonstrates a steadily increasing performance in written communication by students through their co-op terms. As shown in Figure 1, employers generally give ratings of 5, 6, or 7 (Very Good to Excellent) to the engineering students they employ (with all engineering students binned into the results shown regardless of program).

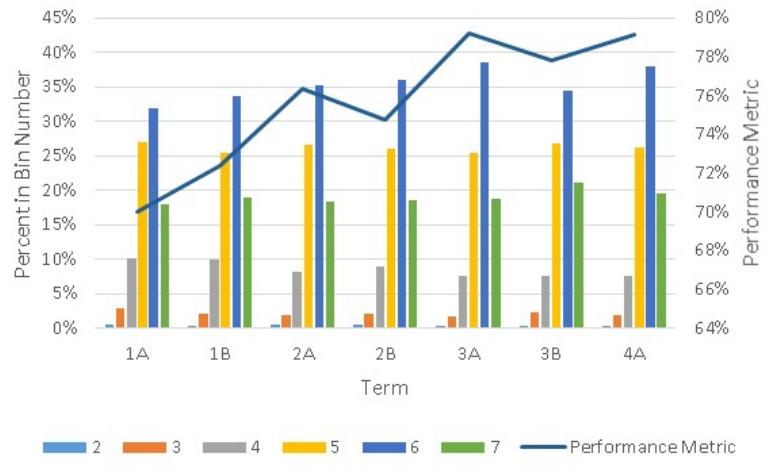

Figure 1: Students Evaluation forms, answer to written communication statement

To aid in making sense of the data, a performance metric is also plotted in Figure 1, calculated as:

Performance Metric $=(A-D) /(A+D)$

where $\mathrm{A}$ is the total percentage of students receiving ratings of 5, 6, or 7 (Very Good to Excellent), and D is the total percentage of students receiving ratings of $1,2,3$, or 4 (Developing to merely 'Good'). Ratings of 'Not Observed are not included in the analysis. The performance metric results further emphasize that Waterloo engineering students are seen by their employers to increase in writing skills over their time in the program. Similar results are found with individual programs, although the data is noisier due to the smaller sample size.

While these findings would suggest that there is no problem with written communication within our programs, further examination suggests that the picture is not as rosy. First, there are concerns that co-op employers may rate students higher than they actually perform for multiple reasons [1]. There are also concerns about subjectivity of the assessment tool. To improve the employer evaluation form, we propose reducing its subjectivity and normalizing the evaluation across student level. For example, expectation descriptors may be revised or expanded (e.g. as rubrics) to align with standards set within a student's academic year of their associated program. Such proposals need to be weighed against the broader realities of a large co-op system that serves the needs of students from all academic programs.

Another concern in terms of the quality of students' written communication as measured by employers is the comparison of employer rating of written communication to other categories on the co-op evaluation. The same analysis for all categories of the employer evaluation is presented in Figure 2. Figure 2 shows that employers rate student more favourably overall than they do in terms of written communication, with the strongest contributors 
being areas such as Interpersonal Communication, Teamwork, and Appreciation of Diversity, while evaluations for criteria such as Problem Solving and Oral and Written Communication are relatively lower. Hence written communication is an area for improvement, especially since UW prides itself on the quality of written communication coming from our graduates.

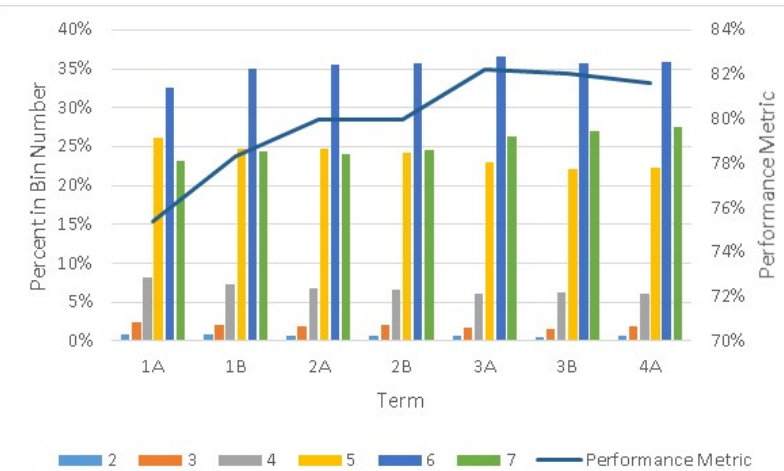

Figure 2: Students Evaluation forms, answer to all categories of evaluation summed.

Concerns about the quality of written communication are also borne out by anecdotal observation of professors on campus, as well as by analysis of work term report grades, as discussed next.

\subsection{Work-Term Reports}

Overall, the evaluations of work-term reports show similar results to co-op employer evaluations. Since each program at UW has its own evaluation method for assessing the co-op reports, we were not able to accommodate an aligned methodology to compare results with the employers' evaluations. As such, in this paper we present an analysis of results for two programs, which we refer to as program 1 and program 2.

Program 1 evaluates co-op reports based on five indicators, as follows:

1- Generate a professional report with correct formatting and appearance

2- Generate a professional report with correct grammar, punctuation and spelling

3- Integrate and explain the use of graphical representations

4- Organize ideas and arguments in a logical manner

As shown in Figure 3, the scores associated with the above indicators increase somewhat over the terms. However, the average grade does not change appreciable, and in fact decreases from $80 \%$ for Work Report 200, down to $78 \%$ for Work Report 300 and 400. Drawing futher conclusions from these data is difficult, as the data is only a snapshot of the students in the program at this time, and does not track cohorts/students moving through various coop terms. Program 1 also feels that they need more data to make a better comparison of trends, but feel anecdotally that students have not improved in written communication as much as they would desire by the time of graduation, as evidenced by the decreasing percentage of students writing at an excellent level (A level) in their second and third work term reports.

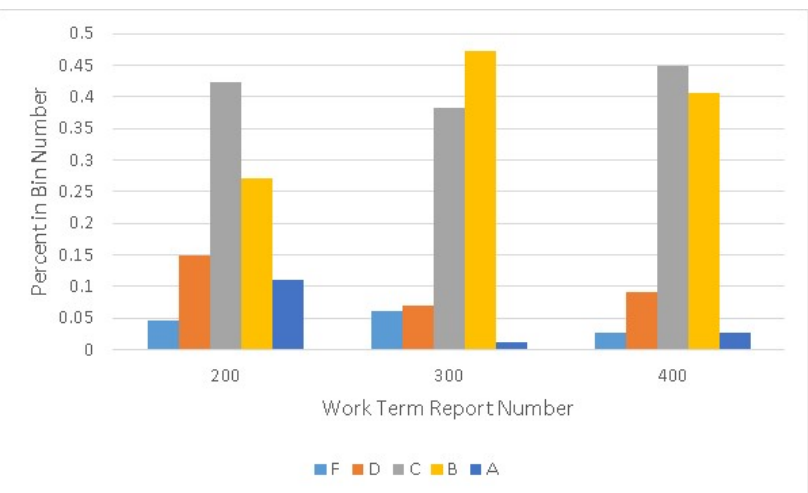

Figure 3: Work-Term Report Evaluations for Engineering program 1.

Carrying on with the analysis we now examine program 2's work report data. At this time, this program records overall grade (composed of effective written communication and quality of engineering analysis), rather than recording each in a granular fashion. As such the data in Figure 4 gives the overall composite grade. The program also grades each level of report (200 level due in second year etc), normed to the level at which students are expected to perform given their year. As such, the distribution term to term should look relatively similar, with an improvement term to term which would relate to the increase in communication skill in students.

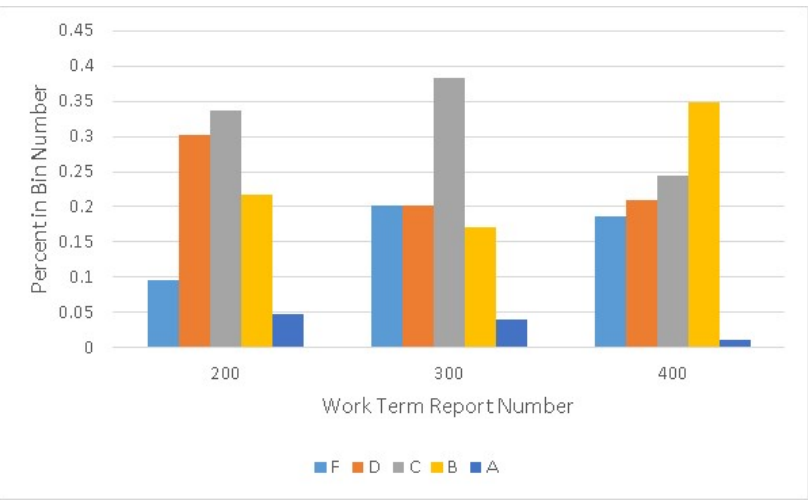

Figure 4: Work-Term Report Evaluations for program 2.

Given this, the data shown in Figure 4 suggests again that students are not improving as much as the program would hope. The average grade neither increases nor decreases 
appreciably across the three terms, ranging from $72 \%$ in Work Report 200, to 69\% in Work Report 300, back to $71 \%$ in Work Report 400. Further, while there are more 400 level student writing at the $\mathrm{B}$ level, there are a worrying number of students writing and a C, D, or F level, and there is a decline from the 200 level to the 400 level in the number of student writing at an A level. Together, these points support the idea that students are not improving to the level that the program wishes them to.

\section{NEXT STEPS}

Much work remains to be done in order to 'close the loop' in terms of assessment of students' communication skills and interventions to improve them. Immediate next steps are to conduct separate focus groups with students and employers.

Discussions with students will focus on questions of the environment in which students write. For example, do they feel that they have sufficient time and guidance to write their work reports? Do they see the value of them? Do they feel they are being marked fairly and being provided with feedback that allows them to improve their writing?

Discussions with employers will focus on questions of how employers view our students writing and the assessment tools we ask them to use. For example, do employers feel/want to be engaged in the work term report process? Do they feel/want to be engaged in the growth in communication skills that our students undergo? Do they view the work term evaluation as a valid measure of students' abilities? Can the evaluation tool be improved? What, if any, attributes would employers like to see improved?

Throughout the above, writing and communication experts are and will be involved to help interpret data and recommend solution through the lens of writing across the curriculum [2, 3]. Recent writing within the discipline interventions [3, 4] are also being analyzed for what effects they may have on the quality of written communication later in the program. It is hoped that the combination of the available data and information from both sets of focus groups will lead to sufficient informed knowledge to suggest improvements to the program, be they in the instruction of writing skills, the structuring of writing assignments, the assessment of writing, or otherwise.

\section{Acknowledgements}

We acknowledge the support we receive from the faculty of engineering at the University of Waterloo, as well as the support of our Departments.

\section{References}

1. Gwyn, Margaret 2016. Incorporating Employer and Student Assessments into a Graduate Attribute Assessment Plan. Proceedings of the Canadian Engineering Education Association, http://dx.doi.org/10.24908/pceea.v0i0.6486

2. Thaiss, Chris; Porter, Tara 2010. The State of WAC/WID in 2010: Methods and Results of the U.S. Survey of the International WAC/WID Mapping Project. College Composition and Communication, v61 n3 p534-570.

3. Russell, David R. 2001. Where do the naturalistic studies of WAC/WID point? A research review. WAC for the new millennium: Strategies for continuing writing-across-the-curriculum programs. Urbana, IL: NCTE. 259-98.

4. Trivett, Andrew; Jewinski, Judi; Collins, Michael; Bermingham, Clare 2015. Writing in the discipline of $M E 100$, Presentation at University of Waterloo Teaching and Learning Conference: OND 2015. 